\title{
A Desirable Aspect in the Variance Premium in a Collective Risk Model
}

\author{
AGUSTÍN HERNÁNDEZ-BASTIDA
}

Departamento Métodos Cuantitativos para la Economía y la Empresa, UNIVERSIDAD DE

GRANADA. SPAIN. E-mail: bastida@ugr.es

Ma DEL PILAR FERNÁNDEZ-SÁNCHEZ

Departamento Métodos Cuantitativos para la Economía y la Empresa, UNIVERSIDAD DE GRANADA.SPAIN. E-mail: pilarfs@ugr.es

\section{EMILIO GÓMEZ-DÉNIZ}

Departamento Métodos Cuantitativos para la Economía y la Empresa, UNIVERSIDAD DE LAS PALMAS DE GRAN CANARIA. SPAIN. E-mail: egomez@ulpgc.es

\begin{abstract}
This paper focuses on the study of the Collective and Bayes Premiums, under the Variance Premium Principle, in the classic Collective Risk Poisson-Exponential Model. A bivariate prior distribution is considered for both the parameter of the distribution of the number of claims and that of the distribution of the claim amount, assuming independence between these parameters. Furthermore, we analyze the consequences on these premiums of small levels of contamination in the structure functions, and find that the premiums are not sensitive to small levels of uncertainty. These results extend the conclusions obtained in Gómez-Déniz et al. (2000), where only variations in the parameter for the number of claims and its effects on premiums were studied.
\end{abstract}

Keywords: Bayes; Modelo colectivo de riesgo; Principio de Varianza; Prima colectiva; Prima Bayes; contaminación..

\section{Un aspecto deseable de la Prima Varianza en el Modelo Colectivo de Riesgo}

\section{RESUMEN}

En este trabajo se estudia un modelo colectivo de riesgo con distribución primaria una distribución de Poisson y distribución secundaria una distribución Exponencial con perfiles de riesgo (los parámetros de las anteriores distribuciones) independientes. Se calculan la Prima Colectiva y la Prima Bayes y se analiza el rango de variación de las Primas indicadas frente a contaminaciones en las funciones estructura (distribuciones a priori). Los resultados aquí obtenidos extienden los de Gómez-Déniz et al (2000), donde se consideraba un modelo solo para la variable número de reclamaciones.

Palabras clave: Bayes, Collective Risk Model, Variance Principle, Collective Premium, Bayes Premium, contamination.

Clasificación JEL: C11

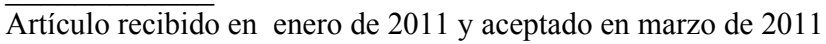

Artículo disponible en versión electrónica en la página www.revista-eea.net, ref. ə-29107 


\section{INTRODUCTION}

The Collective Risk Model (hereafter CRM) is described by a frequency distribution for the number of claims, $K$ and a sequence of independent and identically distributed random variables representing the size of the single claims, $X_{i}$. Frequency $K$ and severity $X_{i}$ are assumed to be independent. Note that the independence assumed here is conditional on the distribution parameters. There is an extensive body of literature on modelling the risk process, see McNeil et al. (2005), among others. In the actuarial framework the random variable of interest is the aggregate claim. The aggregate loss $S$ is the sum of the individual claim sizes, i.e. $S=\sum_{i=1}^{K} X_{i}$, for $K>0$ and 0 for $K=0$. It is well known (see Freifelder (1974); Rolski et al. (1999); Nadarajah and Kotz (2006a, 2006b) and Klugman et al. (2008), among others) that the probability density function of the sum $S$ is given by $\sum_{k=0}^{\infty} p(k \mid \theta) \cdot f^{k^{*}}(x \mid \lambda)$, where $p(k \mid \theta)$ denotes the probability mass function of $K$ and $f^{k^{*}}$ is the k-th convolution of $f(x \mid \lambda)$, the probability density function of the claim size. For the random variable number of claims, a Poisson distribution with parameter $\theta_{1}$ is considered, thus obtaining the compound Poisson distribution. For the claim size an exponential distribution with parameter $\theta_{2}$ is chosen, (hereafter CRM.PE). The excellent study by Panjer and Willmot (1983) shows that the compound Poisson distribution arises in many situations in risk theory and an extensive literature on the question is provided. There is an extensive body of literature about the distribution of the number of claims, primary distribution in the CRM, presenting diverse alternatives, see Grandell (1997), Nikoloulopoulos and Karlis (2008) or Hernández-Bastida et al. (2011), among others.

An important problem in actuarial science is that of premium calculation. There are many different methods to calculate insurance premiums and Goovaerts et al. (1984) consider various classical premium calculation principles. A premium calculating principle is a function $H$ which assigns to a risk $X$ a real number $P=H(X)$, called the premium assigned to the risk $X$. Let $L: R^{2} \rightarrow R$ be a loss function, which assigns to each pair $(x, P) \in R^{2}$ the loss supported by the person who takes action $P$ and obtains result $x$ in a random experiment (see Gerber (1979)). Consequently, the True Individual Premium is defined as follows: Given 
a risk $X$ with distribution function $F(x)$ and a loss function, the True Individual Premium is the value $P$ that minimizes the expected loss $E_{F}[L(x, P)]$ (see Heilmann (1989)). Different loss functions lead to different premium calculation principles. For instance, $L(x, P)=(x-P)^{2}$ leads to the Net Premium Principle and $L(x, P)=x(x-P)^{2}$ leads to the Variance Principle, among others.

This paper focuses on the Variance Premium, whose True Individual Premium is given by $P=E_{F}\left[X^{2}\right] / E_{F}[X]$ although it can also be written as $E_{F}[X]+\left[\operatorname{Var}_{F}(X) / E_{F}[X]\right]$. If $F$ is specified except for a parameter $\theta$ with prior distribution (structure function) $\pi(\theta)$, the Collective Premium is defined as the value $C P$ that minimizes the expected loss $E_{\pi}[L(P, C P)]$, where $P$ is the True Individual Premium. If claim observations are available, the posterior distribution $\pi(\theta \mid x)$ can be obtained and the Bayes Premium is then defined as the value $B P$ that minimizes the expected loss $E_{\pi(\theta \mid x)}[L(P, B P)]$, with $P$ the True Individual Premium. Under the Variance Premium Principle, the following expressions for the Collective and Bayes Premiums are obtained, respectively: $C P=E_{\pi}\left(P^{2}\right) / E_{\pi}(P)$ and $B P=E_{\pi(\theta \mid x)}\left(P^{2}\right) / E_{\pi(\theta \mid x)}(P)$.

When a premium calculating principle is used and the structure functions are specified for the parameters, the Bayes Premium is the best possible estimation of the True Individual Premium. Of course, there is always a certain level of uncertainty in the structure functions specified, and so if a given premium calculating principle presents dramatic variations in the premiums obtained when there are only low levels of uncertainty, this principle will not be considered suitable in practice.

The aim of this paper is to obtain the Collective and Bayes Premiums under the Variance Premium Principle, and to analyze the consequences of small levels of uncertainty in the structure functions on the Collective and Bayes Premiums. A similar analysis for the Net Premium Principle was carried out by Hernández-Bastida et al. (2009) and a special case was developed in Gómez-Déniz et al. (1998). Gómez-Déniz et al. (2000) analyzed the Variance Principle in the unimodal model, which is considered exclusively to the number of claims. 
The paper is organized as follows: Section 2 sets out the model presented. In Section 3 the Collective and the Bayes Premiums in the CRM for the Variance Premium Principle are determined and analyzed the consequences when small levels of contamination in the structure functions are considered. Section 4 summarizes the main conclusions obtained.

Henceforth, ${ }_{p} F_{q}\left(a_{1}, a_{2}, \ldots, a_{p} ; b_{1}, b_{2}, \ldots, b_{k} ; z\right)$ represents the hypergeometric function (see Yakubovich and Luchko (1994); Mathai (1993) or http://functions.wolfram.com).

\section{SETTING OUT THE MODEL}

In the CRM, the likelihood for the Poisson-Exponential pair is well known and is given by $L\left(s \mid \theta_{1}, \theta_{2}\right)=\theta_{1} \theta_{2} e^{-\theta_{1}} e^{-\theta_{2} s} F_{2}\left(1 ; 2,1 ; \theta_{1} \theta_{2} s\right)$ for $s \neq 0$ and $e^{-\theta_{1}}$ for $s=0$. Observe that the usual discontinuity of the CRM at $s=0$ is presented.

In Bayesian analysis, it is necessary to specify a prior distribution for each parameter, and these are normally termed the structure functions. Here, a Gamma distribution is elicited for each one (which in both cases is the conjugate prior distribution) $\pi\left(\theta_{1}\right)=G(a, b)$ and $\pi\left(\theta_{2}\right)=G(c, d)$. Therefore, considering the hypothesis of independence between the parameters, the joint prior distribution is given by $\pi_{0}\left(\theta_{1}, \theta_{2}\right)=\pi_{1} \cdot \pi_{2}$, where the hyper-parameters $a, b, c$ and $d$ are positive, known constants and we assume $c>2$, to ensure the unimodality and the existence of the Collective Premium.

The following expression is obtained by direct integration for the marginal distribution of $s$ given the prior $\pi_{0}$

$$
m\left(s \mid \pi_{0}\right)=\left\{\begin{array}{cc}
\frac{a b^{a} c d_{2}^{c} F_{1}\left(a+1, c+1 ; 2 ; s((b+1)(s+d))^{-1}\right)}{(b+1)^{a+1}(s+d)^{c+1}} & s>0 \\
\left(\frac{b}{b+1}\right)^{a} & s=0
\end{array}\right.
$$

Figure 1 shows the marginal distribution for two different sets of hyperparameters 
Figure 1.

The marginal distribution for $\pi_{0}$ for two sets of hyper-parameters

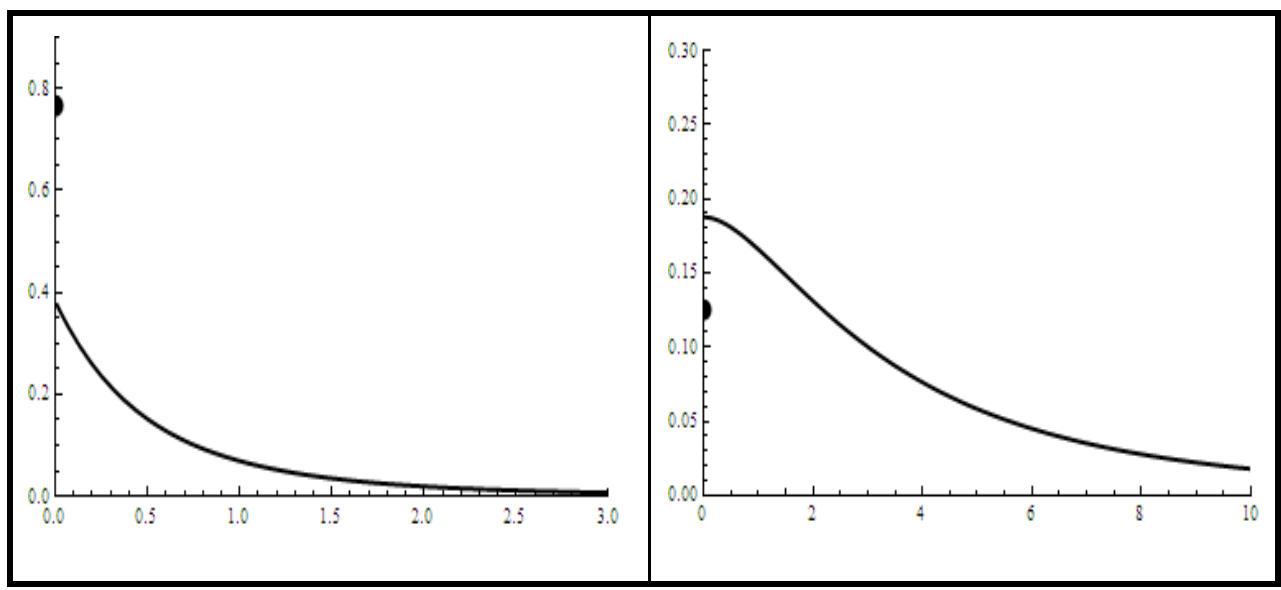

(a) $a=2 ; b=7 ; c=4 ; d=2$ and (b) $a=3 ; b=1 ; c=3 ; d=3$.

When prior distributions for the parameters are elicited there is always a certain level of uncertainty in the elicitation chosen. The structure functions $\pi_{1}$ and $\pi_{2}$ specified above are no exception to this, and so it is essential to first analyze the variation in the quantity of interest, the Bayes Premium, when is caused by a certain level of imprecision in the structure functions. In practice, it is very important that the variation in the Bayes Premium is low enough to prevent a little imprecision in the structure functions from producing dramatic effects on the Bayes Premium. The analysis carried out is based on contamination classes (see Sivaganesan and Berger (1989); Ríos and Ruggeri (1999) and Gómez et al. (2002), among others) in which it is assumed that the prior distribution of the parameter, denoted $\phi$, belongs to a class of possible distributions of probability defined by the contamination of a singular prior distribution, considering various contaminant classes. Specifically, this approach consists in assuming that a singular prior distribution $\pi(\phi)$ is specified for the parameter $\phi$ but that there exists a degree of uncertainty concerning this specification. This uncertainty is quantified by the amount $\varepsilon \in[0,1]$ in other words, it can only be specified that the prior distribution of $\phi$ belongs to a class of probability distributions taking the following form: $G_{\phi}(\pi, \varepsilon)=\left\{\pi^{c}(\phi)=(1-\varepsilon) \pi(\phi)+\varepsilon q(\phi) ; q \in Q\right\}$ where $\pi(\phi)$ is the single prior distribution for $\phi ; \varepsilon \in[0,1]$ is the degree of contamination and $Q$ is the class of contaminant distributions of probability, the definition of which 
incorporates essential aspects of the prior distribution of $\phi$. We shall consider the class of all distributions, denoted as $Q_{1}$, and the class of all unimodal distributions with a fixed, known mode, denoted as $Q_{2}$.

If $\pi_{1 c}=\left(1-\varepsilon_{1}\right) \pi_{1}\left(\theta_{1}\right)+\varepsilon_{1} q_{1}\left(\theta_{1}\right)$ and $\pi_{2 c}=\left(1-\varepsilon_{2}\right) \pi_{2}\left(\theta_{2}\right)+\varepsilon_{2} q_{2}\left(\theta_{2}\right)$ then $\pi_{0}^{\mathrm{lc}}\left(\theta_{1}, \theta_{2}\right)=\pi_{1 c} \cdot \pi_{2}$ is the bivariate distribution in which the uncertainty is with respect to the distribution elicited for $\theta_{1} ; \pi_{0}^{2 c}\left(\theta_{1}, \theta_{2}\right)=\pi_{1} \cdot \pi_{2 c}$ is the bivariate distribution in which the uncertainty is with respect to the distribution elicited for $\theta_{2}$, and $\pi_{0}^{12 c}\left(\theta_{1}, \theta_{2}\right)=\pi_{1 c} \cdot \pi_{2 c}$ is the case in which the contamination is considered with respect to the distribution for both parameters $\theta_{1}$ and $\theta_{2}$.

By direct integration we obtain the marginal distribution of the prior $\pi_{0}^{12 c}$, which is obtained by a linear combination of the marginal distribution for $\pi_{0}$ and the expected values of hypergeometric functions, given by:

For $s \neq 0$,

$$
\begin{aligned}
m\left(s \mid \pi_{0}^{12 c}\right)= & \left(1-\varepsilon_{1}\right)\left(1-\varepsilon_{2}\right) m\left(s \mid \pi_{0}\right) \\
& +\left(1-\varepsilon_{1}\right) \varepsilon_{2} \frac{a b^{a}}{(b+1)^{a+1}} E_{q_{2}}\left[\theta_{2} e^{-\theta_{2} s}{ }_{1} F_{1}\left(a+1 ; 2 ; s \theta_{2}(b+1)^{-1}\right)\right] \\
& +\varepsilon_{1}\left(1-\varepsilon_{2}\right) \frac{c d^{c}}{(s+d)^{c+1}} E_{q_{1}}\left[\theta_{1} e^{-\theta_{1}}{ }_{1} F_{1}\left(c+1 ; 2 ; s \theta_{2}(b+1)^{-1}\right)\right] \\
& +\varepsilon_{1} \varepsilon_{2} E_{q_{1} q_{2}}\left[L\left(s \mid \theta_{1}, \theta_{2}\right)\right]
\end{aligned}
$$

And, for $s=0, m\left(0 \mid \pi_{0}^{12 c}\right)=\left(1-\varepsilon_{1}\right) m\left(0 \mid \pi_{0}\right)+\varepsilon_{1} E_{q_{1}}\left[e^{-\theta_{1}}\right]$.

\section{THE VARIANCE COLLECTIVE AND BAYES PREMIUM}

In this section, we obtain the Collective Premium and the best estimation for the True Individual Premium, i.e the Bayes Premium.

By direct calculus, the True Individual Premium in the CRM.PE model, under the Variance Premium Principle, is equal to $P=\left(\theta_{1}+2\right) / \theta_{2}$.

\subsection{The Collective Premium without and with contamination}

With a little algebra the Collective Premium in this model for the prior $\pi_{0}$ distribution is shown to be equal to a quotient of constants, denoted as 


$$
C P\left[\pi_{0}\right]=\frac{C_{1} C_{2}}{C_{3} C_{4}}
$$

where $C_{1}=\frac{a(a+1)+4 a b+4 b^{2}}{b^{2}} ; C_{2}=\frac{d^{2}}{(c-1)(c-2)} ; C_{3}=\frac{a+2 b}{b}$ and $C_{4}=\frac{d}{c-1}$.

For the prior $\pi_{0}^{12 c}$ distribution, the Collective Premium is given by the following fraction where the numerator and the denominator include the numerator and the denominator of the Collective Premiums for $\pi_{0}$, respectively.

$$
C P\left[\pi_{0}^{12 c}\right]=\frac{\left(1-\varepsilon_{1}\right)\left(1-\varepsilon_{2}\right) C_{1} C_{2}+\operatorname{NCP}\left(\varepsilon_{1}, \varepsilon_{2}, q_{1}, q_{2}\right)}{\left(1-\varepsilon_{1}\right)\left(1-\varepsilon_{2}\right) C_{3} C_{4}+\operatorname{DCP}\left(\varepsilon_{1}, \varepsilon_{2}, q_{1}, q_{2}\right)},
$$

where the term in the numerator is given by

$$
N C P=\left(1-\varepsilon_{1}\right) \varepsilon_{2} C_{1} E_{q_{2}}\left[1 / \theta_{2}^{2}\right]+\varepsilon_{1}\left(1-\varepsilon_{2}\right) C_{2} E_{q_{1}}\left[\theta_{1}+2\right]^{2}+\varepsilon_{1} \varepsilon_{2} E_{q_{1} q_{2}}\left[\left(\theta_{1}+2\right) / \theta_{2}\right]^{2}
$$

and, the denominator is given by

$$
D C P=\left(1-\varepsilon_{1}\right) \varepsilon_{2} C_{3} E_{q_{2}}\left[1 / \theta_{2}\right]+\varepsilon_{1}\left(1-\varepsilon_{2}\right) C_{4} E_{q_{1}}\left[\theta_{1}+2\right]+\varepsilon_{1} \varepsilon_{2} E_{q_{1} q_{2}}\left[\left(\theta_{1}+2\right) / \theta_{2}\right] \text {. }
$$

The range of variation of the $C P\left[\pi_{0}^{12 c}\right]$, when $q_{1}, q_{2} \in Q_{1}$, can be calculated by determining the infimum and the supremum of the following function of two real variables, (see Sivaganesan and Berger (1989) and Gómez-Déniz et al. (2002)).

$$
R_{12}\left(\theta_{1}, \theta_{2}\right)=\frac{\left(1-\varepsilon_{1}\right)\left(1-\varepsilon_{2}\right) C_{1} C_{2}+N R_{12}}{\left(1-\varepsilon_{1}\right)\left(1-\varepsilon_{2}\right) C_{3} C_{4}+D R_{12}}
$$

where

$$
N R_{12}=\left(1-\varepsilon_{1}\right) \varepsilon_{2} C_{1} \theta_{2}^{-2}+\varepsilon_{1}\left(1-\varepsilon_{2}\right) C_{2}\left(\theta_{1}+2\right)^{2}+\varepsilon_{1} \varepsilon_{2}\left(\theta_{1}+2\right)^{2} \theta_{2}^{-2}
$$

and,

$$
D R_{12}=\left(1-\varepsilon_{1}\right) \varepsilon_{2} C_{3} \theta_{2}^{-1}+\varepsilon_{1}\left(1-\varepsilon_{2}\right) C_{4}\left(\theta_{1}+2\right)+\varepsilon_{1} \varepsilon_{2}\left(\theta_{1}+2\right) \theta_{2}^{-1}
$$

It is verified that, $\lim _{\theta_{1} \rightarrow \infty} R_{12}\left(\theta_{1}, \theta_{2}\right)=\infty$ and $\lim _{\theta_{2} \rightarrow 0} R_{12}\left(\theta_{1}, \theta_{2}\right)=\infty$. Accordingly, the superior of the function will be infinity for whatever values $\varepsilon_{1}, \varepsilon_{2}$ strictly positive. As a consequence, the Collective Premium, under the Variance Premium Principle, is extremely sensitive to the structure functions, even if the level of imprecision is small. 


\subsection{The Bayes Premium without and with contamination}

When there is experience of sinistrality, the most appropriate premium is the Bayes Premium. Under the Variance Premium Principle, the Bayes Premium for the $\pi_{0}$ distribution is obtained directly from its definition and is given by the following fraction where, for the sake of simplicity, the argument $s$ is omitted,

$$
B P\left[\pi_{0}\right]=\frac{N_{0}}{D_{0}},
$$

where, the numerator, for $s \neq 0$, is a linear combination of absolutely convergent hypergeometric functions because the independent variable is always less than 1 . Specifically,

$$
\begin{aligned}
N_{0} & =k_{1}(s+d)^{-c+1}{ }_{2} F_{1}\left(a+3, c-1 ; 2 ; s((b+1)(s+d))^{-1}\right) \\
& +k_{2}(s+d)^{-c+1}{ }_{2} F_{1}\left(a+2, c-1 ; 2 ; s((b+1)(s+d))^{-1}\right) \\
& +k_{3}(s+d)^{-c+1}{ }_{2} F_{1}\left(a+1, c-1 ; 2 ; s((b+1)(s+d))^{-1}\right) ;
\end{aligned}
$$

and, for $s=0$ it is equal to

$$
\left(a^{2}+4 b^{2}+4 a b+5 a+8 b+4\right) C_{2}(b+1)^{-2} m\left(0 \mid \pi_{0}\right) .
$$

Analogously, the denominator, for $s \neq 0$, is also a combination of hypergeometric functions

$$
\begin{aligned}
D_{0} & =k_{7}(s+d)^{-c}{ }_{2} F_{1}\left(a+2, c ; 2 ; s((b+1)(s+d))^{-1}\right) \\
& +k_{8}(s+d)^{-c}{ }_{2} F_{1}\left(a+1, c ; 2 ; s((b+1)(s+d))^{-1}\right) ;
\end{aligned}
$$

and, for $s=0$ it is equal to $(a+2 b+2) C_{4}(b+1)^{-1} m\left(0 \mid \pi_{0}\right)$.

The constants $k_{i}$ are given by $k_{1}=\frac{(a+1)(a+2) k_{8}}{2(b+1)^{2}(c-1)} ; k_{2}=\frac{2(a+1) k_{8}}{(b+1)(c-1)}$;

$$
k_{3}=\frac{2 k_{8}}{(c-1)} ; k_{7}=\frac{(a+1) k_{8}}{2(b+1)} \text {, and } k_{8}=\frac{2 a d^{c}}{(b+1)} m\left(0 \mid \pi_{0}\right) \text {. }
$$

For the prior $\pi_{0}^{12 c}$ distribution, the Bayes Premium under the Variance Premium Principle is given by the following fraction where the numerator and the denominator include the numerator and the denominator of the Bayes Premium for $\pi_{0}$, respectively. 


$$
B P\left[\pi_{0}^{12 c}\right]=\frac{\left(1-\varepsilon_{1}\right)\left(1-\varepsilon_{2}\right) N_{0}+N B P\left(\varepsilon_{1}, \varepsilon_{2}, q_{1}, q_{2}, s\right)}{\left(1-\varepsilon_{1}\right)\left(1-\varepsilon_{2}\right) D_{0}+\operatorname{DBP}\left(\varepsilon_{1}, \varepsilon_{2}, q_{1}, q_{2}, s\right)}
$$

where the term in the numerator can be written as

$$
N B P=\left(1-\varepsilon_{1}\right) \varepsilon_{2} E_{q_{2}}\left[N_{1}\left(\theta_{2}\right)\right]+\varepsilon_{1}\left(1-\varepsilon_{2}\right) E_{q_{1}}\left[N_{2}\left(\theta_{1}\right)\right]+\varepsilon_{1} \varepsilon_{2} E_{q_{1} q_{2}}\left[N_{3}\left(\theta_{1}, \theta_{2}\right)\right]
$$

and, the term in the denominator can be written as

$$
D B P=\left(1-\varepsilon_{1}\right) \varepsilon_{2} E_{q_{2}}\left[D_{1}\left(\theta_{2}\right)\right]+\varepsilon_{1}\left(1-\varepsilon_{2}\right) E_{q_{1}}\left[D_{2}\left(\theta_{1}\right)\right]+\varepsilon_{1} \varepsilon_{2} E_{q_{1} q_{2}}\left[D_{3}\left(\theta_{1}, \theta_{2}\right)\right],
$$

respectively. For the sake of simplicity the argument $s$ is omitted in the functions $N_{i}$ and $D_{i}$, which are given by the following expressions involving hypergeometric functions which are absolutely convergent. For each function its value is shown at the point of discontinuity $s=0$.

The following three $N_{i}$ functions that appear in $N B P$ are:

The function $N_{1}\left(\theta_{2}\right)$ given by, for $s \neq 0$,

$$
\begin{aligned}
N_{1}\left(\theta_{2}\right) & =e^{-\theta_{2} s} \theta_{2}^{-1}\left\{k_{41} F_{1}\left(a+3 ; 2 ; s \theta_{2}(b+1)^{-1}\right)+k_{51} F_{1}\left(a+2 ; 2 ; s \theta_{2}(b+1)^{-1}\right)\right. \\
& \left.+k_{61} F_{1}\left(a+1 ; 2 ; s \theta_{2}(b+1)^{-1}\right)\right\}
\end{aligned}
$$

and, for $s=0$ it is $N_{0} C_{2}^{-1} \theta_{2}^{-2}$. Notice that when $\theta_{2}$ tends to zero, the term inside the curly brackets converges to the constant value $k_{4}+k_{5}+k_{6}$ and, accordingly, the $N_{1}\left(\theta_{2}\right)$ function diverges to infinity.

The function $N_{2}\left(\theta_{1}\right)$, given by, for $s \neq 0$,

$$
N_{2}\left(\theta_{1}\right)=\frac{d^{c} e^{-\theta_{1}} \theta_{1}\left(\theta_{1}+2\right)^{2}}{(c-1)(s+d)^{c-1}}{ }_{1} F_{1}\left(c-1 ; 2 ; s \theta_{1}(s+d)^{-1}\right)
$$

and, for $s=0$ it is $C_{2} e^{-\theta_{1}}\left(\theta_{1}+2\right)^{2}$. It can be shown that when $\theta_{1}$ tends to infinity, the function $N_{2}\left(\theta_{1}\right)$ converges to zero.

Finally, the function $N_{3}\left(\theta_{1}, \theta_{2}\right)$ is given by, for $s \neq 0$,

$$
N_{3}\left(\theta_{1}, \theta_{2}\right)=\left(\theta_{1}+2\right)^{2} \theta_{1} e^{-\theta_{1}} \theta_{2}^{-1} e^{-\theta_{2} s}{ }_{1} F_{2}\left(1 ; 2,1 ; \theta_{1} \theta_{2} s\right)
$$

and, for $s=0$ it is $\left(\theta_{1}+2\right)^{2} e^{-\theta_{1}} \theta_{2}^{-2}$. It is verified that when $\theta_{2}$ tends to zero, the $N_{3}\left(\theta_{1}, \theta_{2}\right)$ function diverges to infinity and when $\theta_{1}$ tends to infinity, the function $N_{3}\left(\theta_{1}, \theta_{2}\right)$ converges to zero.

The three functions appearing in $D B P$ are given by the following expressions: 
The function $D_{1}\left(\theta_{2}\right)$ is given by, for $s \neq 0$,

$$
D_{1}\left(\theta_{2}\right)=e^{-\theta_{2}}\left\{k_{91} F_{1}\left(a+2 ; 2 ; s \theta_{2}(b+1)^{-1}\right)+k_{10} F_{1}\left(a+1 ; 2 ; s \theta_{2}(b+1)^{-1}\right)\right\}
$$

and, for $s=0$ it is equal to $b^{a}(a+2 b+2)(b+1)^{-1} m\left(0 \mid \pi_{0}\right) \theta_{2}^{-1}$. Observe that when $\theta_{2}$ tends to zero, the function $D_{1}\left(\theta_{2}\right)$ converges, for $s \neq 0$ to a constant value given by $k_{9}+k_{10}$.

The function $D_{2}\left(\theta_{1}\right)$ is given by, for $s \neq 0$,

$$
D_{2}\left(\theta_{1}\right)=d^{c}(s+d)^{-c} \theta_{1}\left(\theta_{1}+2\right)^{2} e^{-\theta_{1}}{ }_{1} F_{1}\left(c ; 2 ; s \theta_{1}(s+d)^{-1}\right)
$$

and, for $s=0$ it is equal to $C_{4}\left(\theta_{1}+2\right) e^{-\theta_{1}}$. It is verified that when $\theta_{1}$ tends to infinity the function $D_{2}\left(\theta_{1}\right)$ converges to zero.

The function $D_{3}\left(\theta_{1}, \theta_{2}\right)$ is given by, for $s \neq 0$,

$$
D_{3}\left(\theta_{1}, \theta_{2}\right)=\left(\theta_{1}+2\right) \theta_{1} \theta_{2} e^{-\theta_{1}} e^{-\theta_{2} s}{ }_{1} F_{2}\left(1 ; 2,1 ; \theta_{1} \theta_{2} s\right)
$$

and, for $s=0$ it is equal to $\left(\theta_{1}+2\right) e^{-\theta_{1}} \theta_{2}^{-1}$.

The constants $k_{i}$ are given by $k_{4}=\frac{(a+1)(a+2) k_{10}}{2(b+1)^{2}} ; k_{5}=\frac{2(a+1) k_{10}}{(b+1)}$; $k_{6}=2 k_{10} ; k_{9}=\frac{(a+1) k_{10}}{2(b+1)}$, and $k_{10}=\frac{2 a}{(b+1)} m\left(0 \mid \pi_{0}\right)$.

\subsection{The variation of the Bayes Premium for the classes $\mathbf{Q}_{1}$ and $\mathbf{Q}_{2}$}

As previously, (see Sivaganesan and Berger (1989) and Gómez-Déniz et al. (2002)), the range of variation of the Bayes Premium $B P\left[\pi_{0}^{12 c}\right]$, when $q_{1}, q_{2} \in Q_{1}$, uncertainty about the distributions for $\theta_{1}$ and $\theta_{2}$, can be calculated by determining the range of variation of the following function of two real variables

$$
B_{12}\left(\theta_{1}, \theta_{2}\right)=\frac{\left(1-\varepsilon_{1}\right)\left(1-\varepsilon_{2}\right) N_{0}+N B_{12}}{\left(1-\varepsilon_{1}\right)\left(1-\varepsilon_{2}\right) D_{0}+D B_{12}},
$$

where, the term in the numerator is given by,

$$
N B_{12}=\left(1-\varepsilon_{1}\right) \varepsilon_{2} N_{1}\left(\theta_{2}\right)+\varepsilon_{1}\left(1-\varepsilon_{2}\right) N_{2}\left(\theta_{1}\right)+\varepsilon_{1} \varepsilon_{2} N_{3}\left(\theta_{1}, \theta_{2}\right),
$$

and, the term in the denominator is given by,

$$
D B_{12}=\left(1-\varepsilon_{1}\right) \varepsilon_{2} D_{1}\left(\theta_{2}\right)+\varepsilon_{1}\left(1-\varepsilon_{2}\right) D_{2}\left(\theta_{1}\right)+\varepsilon_{1} \varepsilon_{2} D_{3}\left(\theta_{1}, \theta_{2}\right) \text {. }
$$


It is verified that for a fixed $\theta_{1}$ the function $B_{12}$ diverges to infinity when $\theta_{2}$ tends to zero. Hence, the superior of the function $B_{12}$ is infinity for any positive $\varepsilon_{1}$ and $\varepsilon_{2}$. In summary, the Variance Bayes Premium is extremely sensitive to contamination in the prior distributions. On examining the cases of contamination in $\pi_{1}$ or in $\pi_{2}$, separately, it can be seen that:

(i) For $\varepsilon_{2}=0$, contamination only in $\pi_{1}$, the function $B_{12}$ is reduced to a single real variable function with a finite supremum and infimum, in accordance with Gómez-Déniz et al. (2002).

(ii) For $\varepsilon_{1}=0$, contamination only in $\pi_{2}$, the function $B_{12}$ is reduced to a single real variable function with a infinite supremum.

Figure 2 illustrates these cases:

Figure 2.

The functions $B_{1}$ and $B_{2}$ for two sets of hyperparameters

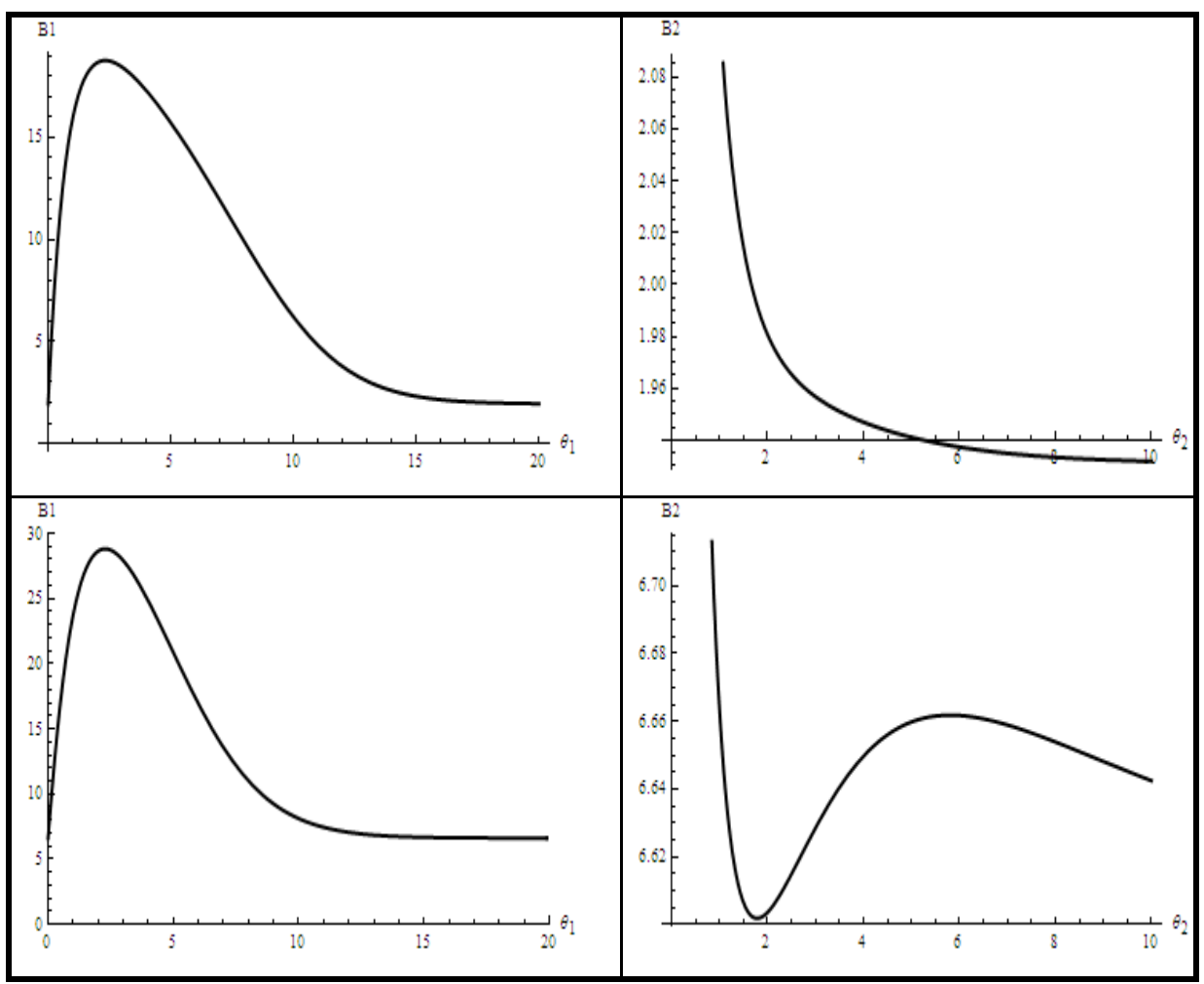

(a),(c): $a=2 ; b=7 ; c=4 ; d=2 ; s=0.5 ; \quad \varepsilon_{1}=0.1$ and (b),(d): $a=3 ; b=1 ; c=3 ; d=3 ; s=0.5 ; \quad \varepsilon_{2}=0.1$ 
Accordingly, we conclude that the extreme sensibility of the $B P\left[\pi_{0}^{12 c}\right]$ is caused by the contamination in the $\pi_{2}$ distribution.

It is clear that the class of the contaminations $Q_{1}$ is fairly broad and contains non-reasonable distributions. Hence, we shall consider the class of unimodal contaminations $Q_{2}$, with a fixed mode, and study the parameter $\theta_{2}$.

The $\pi_{2}$ distribution with $c>2$, is unimodal with the mode at $m=(c-1) / d$. $Q_{2}$ denotes the class of unimodal distributions with the mode at $m$. To analyze the problem of contamination in the $\pi_{2}$ distribution with the class $Q_{2}$, we use the following characterization for the unimodal distributions in accordance with Khintchine (see Feller (1971), for details).

Let $q_{2} \in Q_{2}$ be a unimodal distribution with the mode at $m$ and where $h\left(\theta_{2}\right)$ is a function of $\theta_{2}$. Then, it is verified that $E_{q_{2}}[h]=E_{F}\left[h^{*}(z)\right]$ where $F(z)$ is a distribution function and $h^{*}(z)=\frac{1}{z} \int_{m}^{m+z} h\left(\theta_{2}\right) d \theta_{2}$, for $z \neq 0$, and $h^{*}(z)=h(m)$ for $z=0$.

Using the above characterization the range of variation of the Variance Bayes Premium for the $\pi_{0}^{2 c}=\pi_{1} \cdot \pi_{2 c}$ distribution when $q_{2} \in Q_{2}$ can be determined (see Sivaganesan and Berger (1989) and Gómez-Déniz et al. (2002)), evaluating the supremum and the infimum of the following one real variable function,

$$
B^{*}(z)=\frac{\left(1-\varepsilon_{2}\right) N_{0}+\varepsilon_{2} N_{1}^{*}(z)}{\left(1-\varepsilon_{2}\right) D_{0}+\varepsilon_{1} D_{1}^{*}(z)},
$$

where the functions $N_{1}^{*}(z)$ and $D_{1}^{*}(z)$ are obtained from the functions $N_{1}\left(\theta_{2}\right)$ and $D_{1}\left(\theta_{2}\right)$ using Khintchine's characterization. For this determination the following affirmations are useful.

The first affirmation refers to a straightforward integration by parts by means of induction, allow us to affirm that, when $m$ and $z$ are real numbers with $z>0$, and $n$ is a positive integer, it is verified that $\int_{m}^{m+z} e^{-\theta_{2} s} \theta_{2}^{n} d \theta_{2}=U_{n}(m)-U_{n}(m+z)$, where $U_{n}(r)=e^{-r s} \sum_{k=0}^{n} \frac{n ! r^{n-k}}{(n-k) ! s^{k+1}}$.

The second and third affirmations refer to the integrals that include an exponential and a hypergeometric function, which, when $m$ and $z$ are positive and real numbers, are given by the following: 


$$
\begin{aligned}
I_{\beta}(z) & =\int_{m}^{m+z} \frac{e^{-\theta_{2} s}}{\theta_{2}}{ }_{1} F_{1}\left(\beta ; 2 ; s \theta_{2}(b+1)^{-1}\right) d \theta_{2}=\int_{m}^{m+z} \frac{e^{-\theta_{2} s}}{\theta_{2}} d \theta_{2}+\frac{\left[e^{-m s}-e^{-(m+z) s}\right] \beta}{2(b+1)} \\
& +\frac{s}{\Gamma(\beta)(b+1)} \sum_{n=1}^{\infty} \frac{\Gamma(\beta+n+1) s^{n}}{(n+2) !(n+1) !(b+1)^{n}}\left[U_{n}(m)-U_{n}(m+z)\right],
\end{aligned}
$$

and,

$$
\begin{aligned}
J_{\beta}(z) & =\int_{m}^{m+z} e^{-\theta_{2} s}{ }_{1} F_{1}\left(\beta ; 2 ; s \theta_{2}(b+1)^{-1}\right) d \theta_{2}=\frac{e^{-m s}-e^{-(m+z) s}}{s} \\
& +\frac{1}{\Gamma(\beta)} \sum_{n=1}^{\infty} \frac{\Gamma(\beta+n) s^{n}}{(n+1) !(n) !(b+1)^{n}}\left[U_{n}(m)-U_{n}(m+z)\right] .
\end{aligned}
$$

Using the above affirmations, the term of the numerator in $B^{*}(z)$ can be written as $N_{1}^{*}(z)=\frac{1}{z} \int_{m}^{m+z} N_{1}\left(\theta_{2}\right) d \theta_{2}=\frac{1}{z}\left\{k_{4} I_{a+3}(z)+k_{5} I_{a+2}(z)+k_{6} I_{a+1}(z)\right\}$ for $s \neq 0$ and, $N_{1}^{*}(0)=N_{1}(m)$ and, the term of the denominator in $B^{*}(z)$ as $D_{1}^{*}(z)=\frac{1}{Z} \int_{m}^{m+z} D_{1}\left(\theta_{2}\right) d \theta_{2}=\frac{1}{Z}\left\{k_{9} J_{a+2}(z)+k_{10} J_{a+1}(z)\right\}$ and, $D_{1}^{*}(0)=D_{1}(m)$.

It can be verified that the variation in the function $B^{*}(z)$ is bounded, i.e., the superior and the inferior are finite. Accordingly, we do not obtain the same conclusion than in the class of contamination $Q_{1}$ of all distributions. When, the class of contamination is $Q_{2}$, that maintains the essential aspect of the unimodality in the prior information, the behavior of the Bayes Premium is reasonable with respect to a certain level of uncertainty of the structure function.

Figure 3 illustrates the values of the function $B^{*}(z)$ for two sets of hyperparameters and two levels of uncertainty. 
Figure 3.

The functions $B^{*}(z)$ for two sets of hyperparameters and levels of contamination (a):

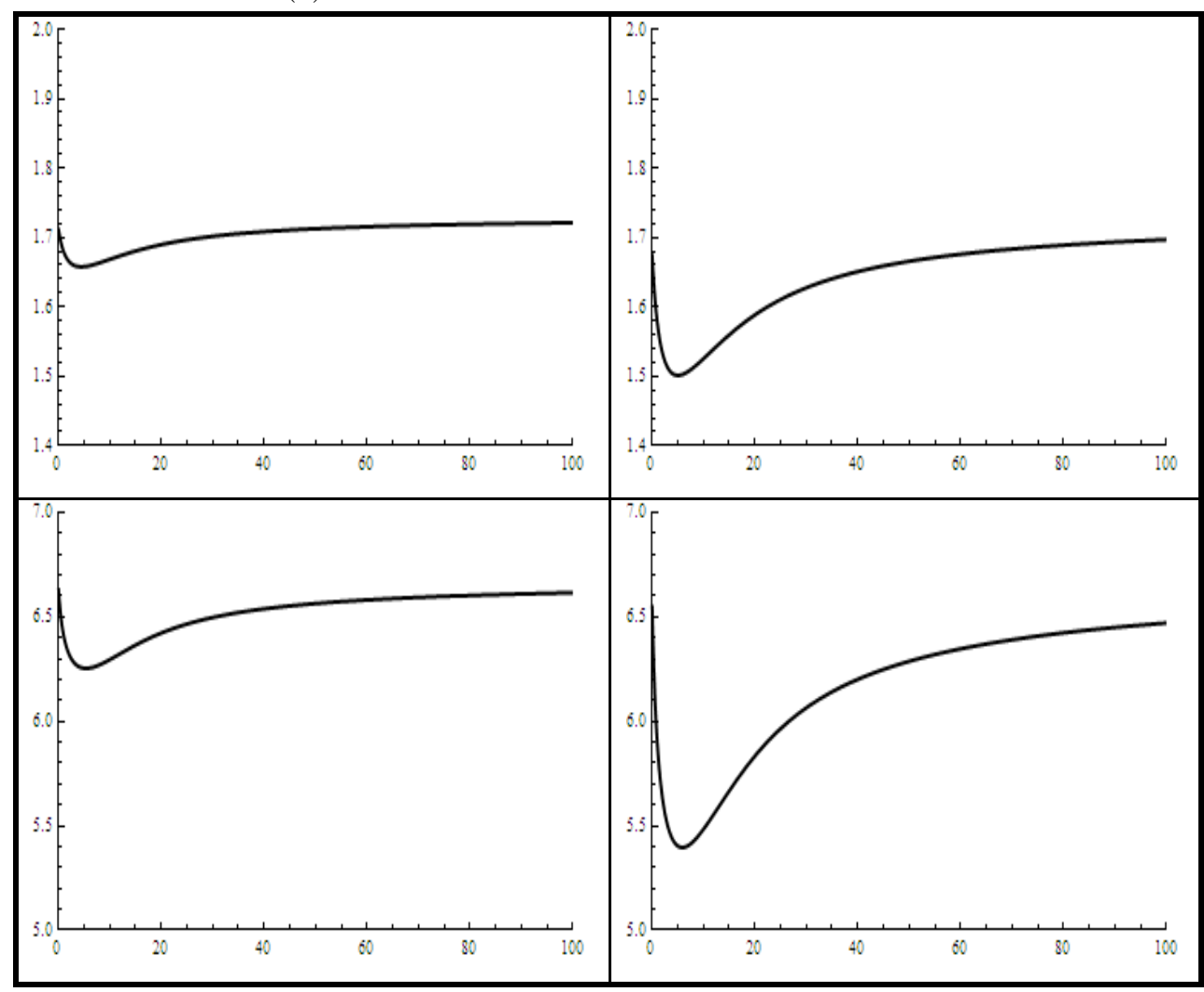

$a=2 ; b=7 ; c=4 ; d=2 ; m=1.5 ; s=0.2 ; \quad \varepsilon_{1}=0.1 ;(b): a=2 ; b=7 ; c=4 ; d=2 ; m=1.5 ; s=0.2 ; \quad \varepsilon_{1}=0.3 ;(c): a=3$; $b=1 ; c=3 ; d=3 ; m=0.67 ; s=0.6 ; \quad \varepsilon_{2}=0.1$ and $(d): a=3 ; b=1 ; c=3 ; d=3 ; m=0.67 ; s=0.6 ; \varepsilon_{2}=0.3$

Finally, to illustrate the amount of variation of the Variance Bayes Premium, when the class of contamination is $Q_{2}$, we determine the RS factor of Sivaganesan (Sivaganesan (1991)), which is given by $\frac{\sup _{q_{2} \in Q_{2}} B P\left(\pi_{0}^{12 c}\right)-\inf _{q_{2} \in Q_{2}} B P\left(\pi_{0}^{12 c}\right)}{2 B P\left(\pi_{0}\right)} \times 100 \%$.

Figure 4 shows the values of this factor for two sets of hyper-parameters, as a function of the aggregate loss and the level of contamination. 
Figure 4

The RS factor as a function of the aggregate loss $\left(\varepsilon_{2}=0.15\right)$ and the level of contamination ( $\mathrm{s}=0.2$ ), for two sets of hyperparameters.

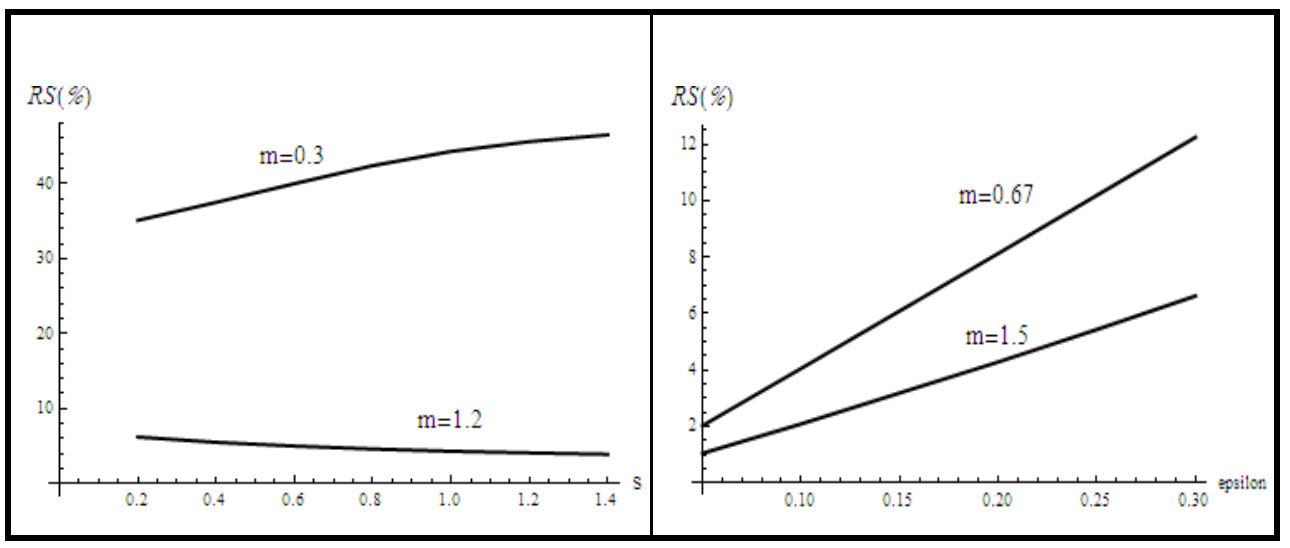

The left side of the Figure 4 shows that for a level of contamination of 15\%, the RS factor is around $6 \%$ when $s=0.2$. The right side of the figure examines this desfavorable case, when $s=0.2$ for several levels of contamination, and the RS factor, which increases as it was expected, reaches values around $12 \%$ when a notable level of contamination $(30 \%)$ is presented.

\section{CONCLUSIONS}

The Collective Risk model with Poisson and exponential distribution as the primary and secondary distributions, respectively, is developed, assuming that the risk profiles $\theta_{1}$ and $\theta_{2}$ are independent. The Bayes Premium (BP) under the Variance Premium Principle is determined and its range of variation is analyzed when the marginal prior distributions for $\theta_{1}$ and $\theta_{2}$ present levels of contamination with contaminant classes given by $Q_{1}$ (class of all distributions) and $Q_{2}$ (class of the unimodal distributions with the same mode as the prior marginal distributions). When the contaminant class is $Q_{1}$ the Variance Premium is extremely sensitive to uncertainty in the prior specification in opposite to the Net Premium Principle, see Hernández-Bastida et al. (2009).

$Q_{1}$ is extremely large and contains several unreasonable distributions, hence $Q_{2}$ is considered, which means to conserve the property of unimodality (and the value of the mode), and in this case, the Variance Principle is very robust, extending the conclusions obtained in Gómez-Déniz et al.(2000). 
Acknowledgements: $A H B$ and EGD thank the Spanish Ministry of Education and Science (project ECO-2009-14152) for partial support of this study. The authors also are grateful to the editor and the referees for their valuable comments which have helped in improving the paper.

\section{REFERENCIAS BIBLIOGRÁFICAS}

FELLER, W. (1971): An Introduction to Probability Theory and Its Applications. New York: John Wiley.

FREIFELDER, F. (1974): Statistical decision theory and procedures. New York: Academic Press.

GERBER, H.U. (1979): An introduction to mathematical risk theory. Huebner Foundation, Monograph: Vol. 8.

GÓMEZ-DÉNIZ, E; HERNÁNDEZ-BASTIDA, A. Y VÁZQUEZ-POLO, F. (1998):"Un análisis de sensibilidad del proceso de tarificación en los seguros generales" en Estudios de Economía Aplicada, 9, pp. 19-34.

GÓMEZ-DÉNIZ, E; HERNÁNDEZ-BASTIDA, A. Y VÁZQUEZ-POLO, F. (2000): "Robust Bayesian Premium in Actuarial Science" en Journal of the Royal Statistics Society. Series D, 49: pp. 1-12.

GÓMEZ-DÉNIZ, E; HERNÁNDEZ-BASTIDA, A. Y VÁZQUEZ-POLO, F. (2002): "Bounds for ratio of posterior expectations. An application in the collective risk model" en Scandinavian Actuarial Journal, 1: pp. 37-44.

GOOVAERTS, M.J.; DE VYLDER, F. AND HAEZENDOCK, J. (1984): Insurance Premiums: Theory and Applications. Amsterdam: North-Holland.

GRANDELL, J. (1997): Mixed Poisson Processes. New York: Chapman and Hall.

HEILMANN, W. (1989): "Decision theoretic foundations of credibility theory" en Insurance Mathematics and Economics, 8, pp. 77-95.

HERNÁNDEZ-BASTIDA, A.; FERNÁNDEZ-SÁNCHEZ, M.P. Y GÓMEZ-DÉNIZ, E. (2011) "Collective Risk model: Poisson-Lindley and exponential distributions for Bayes premiums and operational risk" en Journal of Statistical Computation and Simulation, DOI:10.1080/00949650903486609.

HERNÁNDEZ-BASTIDA, A.; GÓMEZ-DÉNIZ, E. Y PÉREZ-SÁNCHEZ, J.M. (2009): "Bayesian Robustness of the Compound Poisson Distribution under Bidimensional Prior: an Application to the Collective Risk Model" en Journal of Applied Statistics, 36, pp. 853-859.

KLUGMAN, S.A.; PANJER, H.H. Y WILLMOT, G.E. (2008): Loss Models: From Data to Decisions. New York: John Wiley and Sons. 
MATHAI, A.M. (1993): A Handbook of Generalized Special Functions for Statistical and Physical Sciences. Oxford: Clarender Press.

MCNEIL, A.J; FREY, R. Y EMBRECHTS, P. (2005): Quantitative Risk Management: Concepts, Techniques and Tools, Princeton University Press.

NADARAJAH, S. Y KOTZ, S. (2006a):"Compound mixed Poisson distributions I" en Scandinavian Actuarial Journal, 3: pp.141-162.

NADARAJAH, S. Y KOTZ, S. (2006b) "Compound mixed Poisson distributions I" en Scandinavian Actuarial Journal, 3: pp.163-181.

NIKOLOULOPOULOS, A.K. AND KARLIS, D. (2008): "On modeling count data: a comparison of some well known discrete distributions" en Journal of Statistical Computation and Simulation, 78,3, pp. 437-457.

PANJER, H. Y WILMOT, G. (1983): "Compound Poisson Models in Actuarial Risk Theory" en Journal of Econometrics, 23, pp.63-76.

RíOS, D. Y RUGGERI, F. (2000): "Robust Bayesian analysis" en Lecture Notes in Statistics,New York: Springer.

ROLSKI, T.; SCHMIDLI, H.; SCHMIDT, V. Y TEUGEL, J. (1999): Stochastic processes for insurance and finance. John Wiley and Sons.

SIVAGANESAN, S. Y BERGER, O. (1989): "Ranges of posterior measures for priors with unimodal contaminations", en Annals of Statistics, 17: pp. 868889.

SIVAGANESAN, S. (1991): "Sensitivity of some posteriors when the prior is unimodal with specified quantiles" en Canadian Journal of Statistics, 19: pp. 57-65.

YAKUBOVICH, S.B. Y LUCHKO, Y.F. (1994): The Hypergeometric Approach to Integral Transform and Convolution. London: Kluwer Academic Publisher. 
